\title{
Результаты испытания новых перспективных сортов картофеля
}

\section{Х.X. Апшев, Н.А. Тимошина, Е.В. Князева, Л.С. Федотова}

В работе представлена характеристика восьми новых сортов картофеля отечественной селекции ранней и среднеранней групп спелости: Кладезь, Корчма, Кралек, Купец, Патриот, Призер, Третьяковка, Эликсир. Продуктивность новых сортов выше стандартов на 1,5-14,7 т/га, они характеризуются высокой крахмалистостью и содержанием витамина С, отличным вкусом, низким содержанием нитратов и средним - редуцирующих сахаров. Особого внимания заслуживают сорта Кралек (розовая мякоть) и Эликсир (красная мякоть) для диетического питания с повышенным содержанием антоцианов (антиоксидантов) и отличным вкусом.

Ключевые слова: картофель, сорта, продуктивность, вкус, биохимические показатели.

$\mathrm{H}$ еобходимость выведения новых сортов картофеля объясняется как вызовами времени (изменение климатических условий, расширение ареалов болезней), так и новыми требованиями к сортам для переработки на картофелепродукты, и повышением спроса на столовые сорта для диетического питания [1]

Цель исследований: создать новые сорта картофеля с высокими хозяйственно ценными признаками продуктивности, адаптивности, устойчивости к стрессам.

Условия, материал и методы исследований. Сорта картофеля: Кладезь, Кралек, Купец, Корчма, Патриот, Призер, Третьяковка, Эликсир - выведены в условиях Московской области, на территории научно-экспериментальной базы ВНИИКХ «Коренево» Люберецкого района Московской области.

Агротехника выращивания картофеля включала элементы голландской технологии. Гребни формировали фрезерным гребнеобразователем ПКЕ-3000. Предшественники зерновые культуры. По мере роста и развития растений картофеля проводили обработки ботвы инсектицидами и фунгицидами против личинок колорадского жука (препарат Актара в дозе 60 г/га) и фитофтороза (препараты: Акробат МЦ в дозе 2 кг/га и Дитан М45 в дозе 1,5 кг/га). Через 10-12 дней после формирования гребней почву обрабатывали гербицидом избирательного действия (Лазурит в дозе 1,5 кг/га).

Почва опытного участка - дерново-слабоподзолистая супесчаная, нор- мального увлажнения. Пахотный слой характеризовался высокой обменной и гидролитической кислотностью $\left(\mathrm{pH}_{\text {ксІ }}\right.$ $=4,6-4,9 ; \mathrm{H}_{г}=3,5-4,1$ мг-экВ $/ 100$ г почвы); низкой суммой поглощенных оснований и степенью насыщенности ими (S = 2,2-3,9 мг-экв/100 г почвы; $V$ =34,7$52,7 \%)$; высоким содержанием подвижного фосфора (265-378 мг/кг почвы) и средним и ниже среднего содержанием обменного калия (105-154 мг/кг почвы); содержание гумуса 1,7-2,4\%.

Весной перед посадкой картофеля вносили среднюю дозу нитроаммофоски $(16: 16: 16)$ из расчета 600 кг/га по физической массе или $\mathrm{N}_{96} \mathrm{P}_{96} \mathrm{~K}_{96}$ кг/га д.в.

Содержание крахмала в клубнях определяли по удельному весу (ГОСТ 7194-81) и [2]; витамина С - по И. К. Мурри [4, 6]; редуцирующие сахара по методу Самнера [3]; растворимый белок - рефрактометрическим методом [4]; нитраты - ионометрически по ГОСТ 29270-95. Вкусовые качества оценивали по методике определения столовых качеств картофеля ВИР 1969 года по пятибалльной шкале вкуса вареного картофеля: 5 - отличный вкус, 4-хороший, 3 - удовлетворительный, 2 - пресный, 1 - плохой (неприятный, горьковатый) [5].

Результаты исследований. Представляемые сорта картофеля различались по хозяйственнобиологическим и морфологическим признакам.

Кладезь - среднеранний, столовый. Высокоурожайный, товарность 96\%. Содержание крахмала 15-17\%. Вкусовые качества хорошие и отличные (4,5-5,0 баллов). При варке клуб- ни среднеразваристые, не темнеющие. Лежкость хорошая. Сорт устойчив к раку, вирусным болезням, бактериозам, парше, альтернариозу. Устойчивость к фитофторозу по листьям повышенная (5-7 баллов), по клубням - высокая. Устойчив к механическим повреждениям, жаре и засухе, высоко отзывчив на плодородие почв. Проходит Государственное сортоиспытание.

Корчма - ранний, столовый. Клубни красные, округло-овальные, гладкие с мелкими глазками. Мякоть светло-желтая. Отличается высокой урожайностью (до 45 т/га), содержание крахмала 12,5-13,0\%. Отличные вкусовые качества (5,0 баллов) сохраняются долго (до 8 месяцев). При варке клубни рассыпчатые и не темнеющие. Лежкость хорошая. Устойчив к раку, нематоде, вирусным болезням, парше, ризоктониозу, альтернариозу, бактериозам, механическим повреждениям, жаре и засухе. Устойчивость к фитофторозу по листьям повышенная, по клубням высокая. Ценность сорта: стабильная и высокая урожайность, пригодность для ранней продукции, отличный вкус. Сорт планируется для передачи в Государственное сортоиспытание.

Кралек (рис. 1) среднеранний, столовый для диетического питания. Высокоурожайный, содержание крахмала 12-15\%. Вкусовые качества отличные, клубни при варке рассыпчатые не темнеющие. Отличается повышенным содержанием антиоксидантов. Устойчивость к фитофторозу, вирусным болезням и бактери-

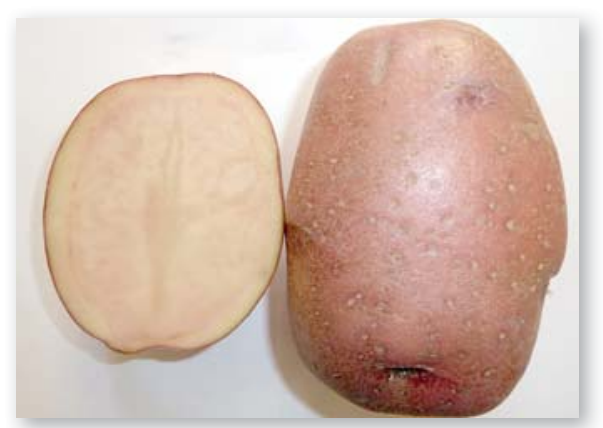

Рис. 1. Сорт Кралек (Красный лекарь), для диетического питания 
озам повышенная, отзывчив на плодородие почв. Ценность сорта: хорошая и стабильная урожайность, высокое содержание антиоксидантов. Сорт планируется для передачи в Государственное сортоиспытание.

Купец - ранний, столовый. Урожайность очень высокая, содержание крахмала 12,5-16,8\%. Вкусовые качества хорошие, при варке не разваривается, не темнеет. Лежкость хорошая. Устойчив к раку, вирусам, ризоктониозу, альтернариозу, механическим повреждениям. Среднеустойчив к фитофторозу по листьям и относительно высоко - по клубням. Слабо поражается паршой обыкновенной. Отличается хорошей переносимостью жары и засухи, отзывчивостью на плодородие. Сорт находится в Государственном реестре РФ.

Патриот - среднеранний, столовый. Урожайность высокая, содержание крахмала 12,5-13,4\%. Клубни крупные, округло-овальные, розовые. Мякоть светло-желтая. Вкусовые качества хорошие, при варке клубни не развариваются и не темнеют. Лежкость хорошая. Устойчив к раку, к вирусным болезням и фитофторозу устойчивость повышенная, к парше обыкновенной и бактериозам - высокая. Устойчив к механическим повреждениям и засухе. Сорт находится в Государственном реестре РФ.

Призер - среднеранний, столового назначения. Клубни крупные, округло-овальные. Окраска кожуры и мякоти - светло-желтая. Масса товарного клубня 100-150 г. Урожайность высокая - до 50 т/га, товарность 98\%. Содержание крахмала 12-14\%.
Вкус и лежкость хорошие. Сорт устойчив к раку, к фитофторозу, вирусам, альтернариозу, парше, бактериальным болезням устойчивость повышенная, также устойчив к механическим повреждениям. Сорт находится в Государственном реестре РФ.

Третьяковка - среднеранний, столовый. Высокоурожайный (50 т/га и более), содержание крахмала 1518\%. Отличные вкусовые качества сохраняет долго (более 8 месяцев), лежкость хорошая. Устойчив к раку, вирусным болезням, парше, бактериозам, золотистой цистообразующей нематоде, обладает повышенной устойчивостью к фитофторозу по листьями и высокой - по клубням. Сорт передан в Государственное сортоиспытание.

Эликсир (рис. 2) - среднеранний, для диетического питания. Высокоурожайный (более 45 т/га), содержание крахмала 13,0-14,5\%, многоклубневый. Вкусовые качества хорошие. При варке среднеразваристый, не темнеющий. Лежкость хорошая. Устойчив к раку, механическим повреждениям, устойчивость к вирусным болезням, парше, ризоктониозу, бактериозам - повышенная. Среднеустойчив к фитофторозу по листьям и высокоустойчив по клубням. Сильно отзывчив на плодородие почв, хорошо выдерживает жару и засуху. Сорт планируется для передачи в Государственное сортоиспытание.

По экспериментальным данным за шесть лет наблюдений (20122016 годы) установлено, что представляемые сорта картофеля превосходят соответствующие стандар-

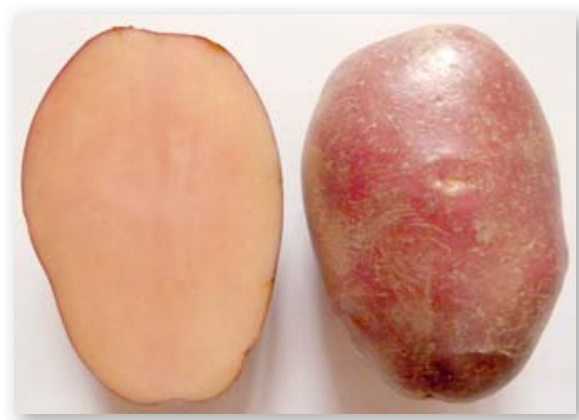

Рис. 2. Сорт Эликсир, для диетического питания

ты как по урожайности, так и по биохимическому составу (табл.).

Наиболее крахмалистыми оказались среднеранние сорта картофеля: Кладезь, Призер, Третьяковка и Эликсир - 15,0-15,7\%, против 13,6\% в стандарте (Невский).

Содержание витамина С в представляемых новых сортах колебалось от 21,5 мг\% (Призер) до 35,6 мг\% (Корчма), против 14,7 и 19,3 мг\% в соответствующих стандартах, т.е. практически вдвое превышали контрольные варианты. Наиболее ценные по этому показателю сорта: Кладезь (34,7 мг\%) и Корчма (35,6 мг\%).

Содержание растворимого белка в новых сортах хотя и невысокое (от 1,3\% до 1,5\%), однако, выше значений соответствующих стандартов.

Наибольшее количество редуцирующих сахаров отмечено в картофеле сорта Призер $(2,4 \%)$, а остальные сорта характеризовались средним уровнем $(1,2-1,7 \%)$, что дает возможность рекомендовать их как для целей столового использова-

\section{Сравнительная характеристика перспективных сортов картофеля (среднее за 2012-2016 годы)}

\begin{tabular}{|c|c|c|c|c|c|c|c|c|}
\hline \multirow[b]{2}{*}{ Группа } & \multirow[b]{2}{*}{ Сорт } & \multirow{2}{*}{$\begin{array}{c}\text { Урожайность, } \\
\text { т/га }\end{array}$} & \multicolumn{5}{|c|}{ Содержание } & \multirow[b]{2}{*}{ Вкус, балл } \\
\hline & & & крахмала, \% & $\begin{array}{c}\text { витамина С, } \\
\text { мг\% }\end{array}$ & белка, \% & $\begin{array}{c}\text { редуцированных } \\
\text { сахаров, \% }\end{array}$ & $\begin{array}{c}\text { нитратов, } \\
\text { мг/кг }\end{array}$ & \\
\hline \multirow{3}{*}{ Ранние } & Удача (st) & 38,3 & 13,2 & 14,7 & 1,1 & 1,3 & 103 & 3,5 \\
\hline & Купец (P) & 46,4 & 14,5 & 29,3 & 1,5 & 1,2 & 88 & 4,3 \\
\hline & Корчма (ГП $)^{\star * *}$ & 40,7 & 13,7 & 35,6 & 1,4 & 1,7 & 93 & 4,6 \\
\hline \multirow{7}{*}{ Среднеранние } & Невский (st) & 37,9 & 13,6 & 19,3 & 1,2 & 1,6 & 96 & 4,1 \\
\hline & Кладезь (Исп) ${ }^{*}$ & 43,3 & 15,7 & 34,7 & 1,5 & 1,6 & 81 & 4,7 \\
\hline & Кралек (ГП) *** & 39,4 & 14,3 & 23,5 & 1,3 & 1,5 & 70 & 5,0 \\
\hline & Патриот $(\mathrm{P})^{\star *}$ & 42,5 & 13,9 & 25,3 & 1,7 & 1,6 & 73 & 4,3 \\
\hline & Призер (P)** & 49,8 & 15,0 & 21,5 & 1,3 & 2,4 & 62 & 5,0 \\
\hline & Третьяковка (Исп) ${ }^{*}$ & 52,7 & 15,4 & 26,9 & 1,5 & 1,6 & 67 & 5,3 \\
\hline & Эликсир (Исп)* & 50,9 & 15,0 & 24,3 & 1,4 & 1,6 & 78 & 4,6 \\
\hline \multicolumn{2}{|l|}{$\mathrm{HCP}_{05}$} & 1,3 & 0,5 & 1,7 & 0,3 & 0,5 & 22 & 1,0 \\
\hline
\end{tabular}


ния, так и в производстве хрустящего картофеля.

Вкусовые качества представляемых сортов выше соответствующих стандартов, наиболее вкусными (по пятибалльной шкале) оказалось шесть сортов: Третьяковка, Кладезь, Кралек, Призер, Корчма и Эликсир. Только сорта Купец и Патриот получили оценку 4,3 балла, что выше оценки стандартов, но немного ниже, чем у остальных испытуемых сортов.

Заключение. Таким образом, на основании данных по урожайности и биохимическому составу, нами установлено, что новые сорта картофеля:

- характеризуются высокой продуктивностью (превосходят стандарт на 1,5-14,7 т/га);

- обладают высокой крахмалистостью, содержанием витамина С, отличным вкусом, низким содержанием нитратов и средним - редуцирующих сахаров.

Особого внимания заслуживают сорта Кралек (розовая мякоть) и Эликсир (красная мякоть) для диетического питания с повышенным содержанием антоцианов (антиоксидантов) и отличным вкусом
Библиографический список 1.Методика исследований по культуре картофеля. М.: НИИКХ, 1967. 262 с.

2.Ермаков А.И. и др. Методы биохимического исследования растений. Л.: Колос, 1972. 456 с.

3.Методика физиолого-биохимических исследований картофеля. М.: НИИКХ, 1989. 142 с.

4.Методика определения столовых качеств картофепя. Л.: ВИР, 1969. С. 12

5.Руководство по методам контроля качества и безопасности БАД к пище / Руководство Р 4.1.1672-03. М., 2004. С. 72

6.Пискун Г.И. Роль сорта в инновационном развитии картофелеводства // Картофелеводство: сборник научных трудов. Минск, 2010. Т. 17. С. $66-75$

\section{Об авторах}

Апшев Хусейн Хамидович, канд. c. - х. наук, зав. лаборатории селекции. E-mail: coordinazia@mail.ru

Тимошина Наталья Александровна, канд. с. - х. наук, с.н.с. лаборатории агрохимии и биохимии.

E-mail:coordinazia@mail.ru

Князева Елена Валерьевна, Н.С. лаборатории агрохимии и биохимии E-mail: coordinazia@mail.ru

\section{Федотова Людмила Сергеевна,} доктор с. - х. наук, профессор, зав. лабораторией агрохимии и биохимии.

E-mail: coordinazia@mail.ru

Федеральное государственное бюджетное научное учреждение «Всероссийский научно-исследова- тельский институт картофельного хозяйства им. А.Г. Лорха»

New perspective potatoes varieties and their characteristic

Kh.Kh. Apshev, $P h D$, head of laboratory of plant breeding. E-mail: coordinazia@mail.ru N.A. Timoshina, $P h D$, senior research fellow, laboratory of agrochemistry and biochemistry. E-mail: coordinazia@mail.ru E.V. Knyazeva, research fellow, laboratory of agrochemistry and biochemistry.

E-mail: coordinazia@mail.ru

L.S. Fedotova, DSc, professor, head

of laboratory of agrochemistry and

biochemistry. E-mail: coordinazia@mail.ru

Lorch Potato Research Institute

Summary. The work presents the characteristics of eight new varieties of potato of russian selection of early and early ripening groups: Kladez, Korchma, Kralek, Kupets, Patriot, Prizier, Tretyakovka, Elixir. Productivity of new varieties is 1.5-14.7 t/ha higher than standards. New varieties characterize high starch content, vitamin $C$ content, excellent taste, low nitrate content and medium - reducing sugars. Special attention should be paid to the varieties Kralek (pink pulp) and Elixir (red pulp). These varieties are intended for dietary nutrition and contains anthocyanins (antioxidants). Also they differ excellent taste.

Keywords: potatoes, varieties, taste, productivity, biochemical indicators.
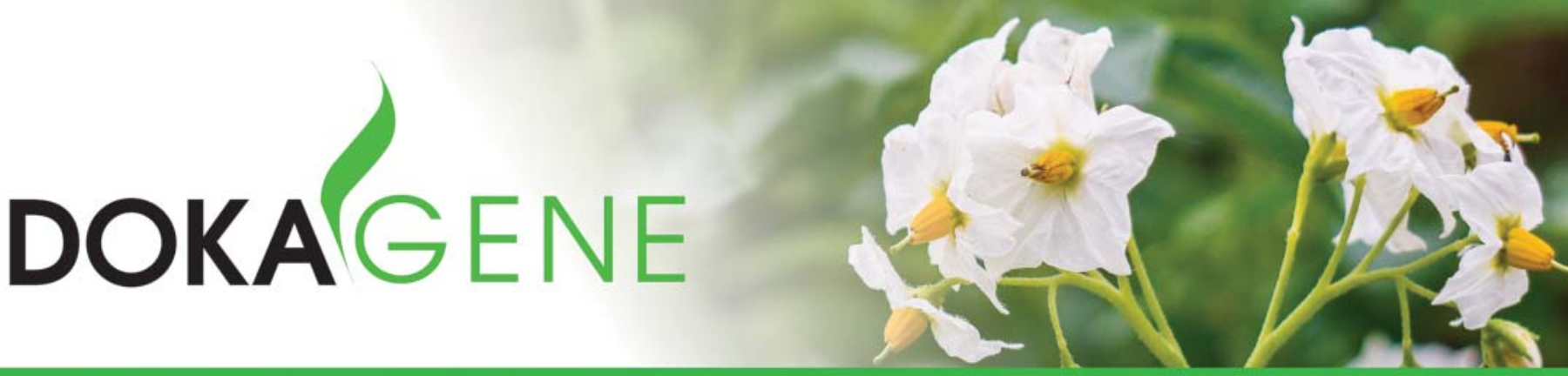

ПРОДАЖА КАЧЕСТВЕННЫХ СЕРТИФИЦИРОВАННЫХ СЕМЯН КАРТОФЕЛЯ САМЫХ ВОСТРЕБОВАННЫХ СОРТОВ

Качество гарантировано партнерством с ведущими селекционными центрами и полным комплексом анализов на ультрасовременной исследовательской базе

ООО «ДГТ», Московская обл. Дмитровский р-ОН, с. Рогачево ул. Московская, стр. 58 www.dokagene.ru
Коммерческий отдел: Роман Кашковал

(D) 8-916-290-03-71

(Q) r.kashkoval@vegetoria.ru

(C) $8-495-226-07-68$ 